\title{
On the origin of microcraters on the surface of ion beam bombarded plant cell walls
}

\author{
M.C. Salvadori ${ }^{a}{ }^{*}$, F.S. Teixeira ${ }^{a}$, I.G. Brown ${ }^{b}$ \\ ${ }^{a}$ Institute of Physics, University of Sao Paulo, C.P. 66318 CEP 05315-970 Sao Paulo, S.P., Brazil \\ ${ }^{b}$ Lawrence Berkeley National Laboratory, Berkeley, California 94720, USA
}

\begin{abstract}
Ion bombardment of plant and bacterial cellular material has recently been used as a tool for the transfer of exogenous DNA macromolecules into the cell interior region. The precise mechanism that leads to the transfer of macromolecules through the cell envelope is not yet clear, however it has been observed that the ion bombardment is accompanied by the formation of "microcraters" on the cell wall, and it is possible that these features provide channels for the macromolecule transfer. Thus the nature and origin of the microcraters is of importance to understanding the DNA transfer phenomenon as well as being of fundamental interest. We report here on some scanning electron microscope observations we have made of onion skin cells that have been subjected to electron beam bombardment of sufficiently high power density to damage the cell wall. The damage seen is much less than and different from the microcraters formed subsequent to ion bombardment. We speculate that the microcraters may originate from the explosive release of gas generated in the biomaterial by ion bombardment.
\end{abstract}

Keywords: Electron microscopy; Ion implantation; Biological material; Cell damage

* Corresponding author. Tel.: +55-11-818-6857; fax: +55-11-818-6749.

E-mail address: mcsalvadori@if.usp.br (M.C. Salvadori). 
Ion beam bioengineering [1] is a relatively new application area of ion beam physics and technology. An interesting and potentially important development that has been demonstrated is the transfer of DNA into both plant cells $[2,3]$ and bacterial cells [4-6] that can be brought about subsequent to ion bombardment of the cells under the appropriate conditions of ion energy and ion fluence. Although the physical mechanism whereby the large DNA macromolecules are transported through the cell wall into the cell interior is not yet understood, it has been observed that microcrater-like structures, of dimension (rim diameter) typically in the hundreds of nanometer range, are formed on the cell wall under the same ion bombardment conditions, and it is thought that these structures might provide pathways for macromolecule flow into the cell $[7,8]$. The origins of ion-beam-induced microcraters are not yet clear, and observations that might help to elucidate the formation processes involved could lead to a fuller understanding of ionbeam-induced DNA transfer as well as to the basic science of ion beam interaction with biological material.

Onion skin cells have frequently been used as convenient cellular material for ion bombardment studies $[8,9]$ because they are large and flat (Fig. 1), and are easily obtained and prepared. When these cells are ion bombarded, for example with $\mathrm{Ar}^{+}$ions at $20-30 \mathrm{keV}$ energy and to a dose of around $1 \times 10^{15}$ ions $/ \mathrm{cm}^{2}$, microcraters are formed, as shown in Fig. 2 [7,8]. To see whether or not similar structures are formed by electron beam bombardment, we mounted onion skin cells such as shown in Fig. 1 in an electron microscope in which the focused but unscanned electron beam was used to damage a particular region of the cell wall surface, and then the SEM operated in the usual scanned mode so as to image the damaged region. The electron beam was $20 \mathrm{keV}$ and the current was varied from a low of $3 \mathrm{pA}$ to a high of $20 \mathrm{nA}$ as indicated in Fig. 3. The exposure time was 2 min in each case. Fig. 3(a) shows the onion skin cell wall prior to electron beam bombardment, and Fig. 3(b) shows the same region after exposure to the focused but unscanned beam at increasing electron beam currents. Eight separate exposures were made, and eight separate damage sites can be recognized, from barely visible to 
substantially damaged. Thus damage to the cell wall can be brought about by the electron beam. The damage includes a small central region of severe damage that is surrounded at sufficiently high beam power by a circular more-lightly-damaged zone of several microns in diameter, but no microcraters are formed.

It is instructive to consider the similarities and dissimilarities between ion bombardment when microcraters are formed and electron bombardment as in the work described here. As is well known, ion beam bombardment gives rise to a collision cascade in the subsurface material. The SRIM code, a Monte-Carlo program, provides a convenient tool for calculation and visualization of the cascade [10], and the results of a SRIM calculation for $20 \mathrm{keV} \mathrm{Ar}^{+}$ions into a substrate that we have taken as $\mathrm{C}_{6} \mathrm{H}_{12} \mathrm{O}_{6}$ as a simple model for onion skin cell wall [8,9] are shown in Fig. 4(a). The interaction volume (collision cascade region) is roughly $20 \mathrm{~nm}$ radius and $100 \mathrm{~nm}$ deep. Electron bombardment of the material by the SEM beam gives rise to an interaction region of similar shape at first glance [11]. Electrons suffer elastic and inelastic collisions and the volume of material filled by electron trajectories is typically microns deep by microns in diameter, orders of magnitude greater than the unscattered beam. Fig. 4(b) shows the results of a Monte Carlo electron trajectory simulation for a $20 \mathrm{keV}$ electron beam in carbon [11]; the interaction volume is roughly $2 \mu \mathrm{m}$ radius and $5 \mu \mathrm{m}$ deep. Note that circular regions of light damage of radius $\sim 5 \mu \mathrm{m}$ can be seen in Fig. 3(b), corresponding to this electron scattering region. Let us compare the energy and power densities injected into the material by ion bombardment and by electron bombardment. For $20 \mathrm{keV} \mathrm{Ar}^{+}$ions to a dose of $1 \times 10^{15} \mathrm{ions} / \mathrm{cm}^{2}$, an implantation time of some minutes per $\mathrm{cm}^{2}$, and assuming that all the energy input by the ion beam is transferred to a surface layer extending $100 \mathrm{~nm}$ below the surface, we estimate an injected energy density of order $10^{5} \mathrm{~J} / \mathrm{cm}^{3}$ and power density of order $10^{3} \mathrm{~W} / \mathrm{cm}^{3}$. For an electron beam with energy $20 \mathrm{keV}$ and current $20 \mathrm{nA}$, and assuming that all the energy input by the electron beam is transferred to a cylindrical volume $\sim 10^{-9} \mathrm{~cm}^{3}$ ( $5 \mu \mathrm{m}$ radius and $5 \mu \mathrm{m}$ long) over a 2 min time period, we estimate an injected energy density of order $10^{8} \mathrm{~J} / \mathrm{cm}^{3}$ and power density 
of order $10^{6} \mathrm{~W} / \mathrm{cm}^{3}$. These estimates are very simplistic and barely order-of-magnitude, but they make clear that the power and energy density deposited by the ion bombardment is vastly less than that deposited by the electron bombardment, over the region of interest. Yet it is the ion bombardment that gives rise to microcraters. These considerations imply (but do not prove) that the microcraters are not simply the consequence of power or energy deposition in the cell wall, but are more specifically related to ion effects.

Micron-sized, crater-shaped pits have been observed in silicon after $\mathrm{Ne}^{+}$ion implantation at $20 \mathrm{keV}$ to a dose $\sim 5 \times 10^{16}$ ions $/ \mathrm{cm}^{2}$, after annealing, an effect attributed to the accumulated neon gas leaving the surface as bubbles [12]. Bearing in mind that for the case of biological material such as cell wall, gas can be evolved not only from the injected ion beam but much more so from dissociation of the bombarded $\mathrm{C}_{6} \mathrm{H}_{12} \mathrm{O}_{6}$ molecules, we speculate that a possible origin of the microcraters observed following ion bombardment of plant cell wall could be a similar bubblelike (or "explosive") release of gas from within the cell wall material. A simple calculation based on the ideal gas law shows that only a very modest fractional dissociation (a few percent) of the cell wall $\mathrm{CHO}$ material by the collision cascade is needed to generate a substantial gas pressure (a few atmospheres) within the cell wall. This gas could accumulate in bubbles throughout the wall until the pressure is sufficient to puncture the outer wall membrane, resulting in microcraters that provide channels to the interior cell region through which large macromolecules such as DNA could flow. Further work is needed to test this hypothesis.

\section{Acknowledgements}

We are grateful to Ms. Somjai Sangyuenyongpipat (Chiang Mai University, Thailand) for the SEM micrograph of Fig. 2. This work was supported by the Fundacao de Amparo a Pesquisa do Estado de Sao Paulo (FAPESP), Brazil, and in part by the U.S. Department of Energy under Contract No. DE-AC03-76SF00098. 


\section{References}

[1] Z. Yu, "Ion Beam Bioenginering”, Springer, New York, 2005 (English translation in press).

[2] Z. Yu, J. Yang, Y. Wu, B. Cheng, J. He, Y. Huo, Nucl. Instr. Meth. Phys. Res.B 80/81 (1993) 1328.

[3] Y. Hase, A. Tanaka, I. Narumi, H. Watanabe, M. Inoue, JAERI Rev. 98-016 (1998) 81.

[4] T. Vilaithong, L.D. Yu, C. Alisi, B. Phanchaisri, P. Apavatjrut, S. Anuntalabhochai, Surf. Coat. Technol. 128/129 (2000) 133.

[5] S. Anuntalabhochai, R. Chandej, B. Phanchaisri, L.D. Yu, T. Vilaithong, I.G. Brown, Appl. Phys. Lett. 78 (2001) 2393.

[6] B. Phanchaisri, L.D.Yu, S. Anuntalabhochai, R. Chandej, P. Apavatjrut, T. Vilaithong, I.G. Brown, Surf. Coat. Technol. 158/159 (2002) 624.

[7] L.D. Yu, B. Phanchaisri, P. Apavatjrut, S. Anuntalabhochai, T. Vilaithong, I.G. Brown, Surf. Coat. Technol. 158/159 (2002) 146.

[8] S. Sangyuenyongpipat, T. Vilaithong, L.D. Yu, A. Verdaguer, I. Ratera, D.F. Ogletree, O.R. Monteiro, I.G. Brown, Nucl. Instr. Meth. Phys. Res. B 227 (2005) 289.

[9] L.D. Yu, T. Vilaithong, B. Phanchaisri, P. Apavatjut, S. Anuntalabhochai, P. Evans and I.G. Brown, Nucl. Instrum. Meth. Phys. Res. B 206 (2003) 586.

[10] See the website www.SRIM.com

[11] See, for instance, J. I. Goldstein et al, "Scanning Electron Microscopy and X-Ray Analysis" (Plenum, New York, 1981).

[12] A.Markwitz, V.J. Kennedy and H. Baumann, Nucl. Instrum. Meth. Phys. Res. B 206 (2003) 179. 


\section{Figure Captions}

Fig. 1 SEM photograph of onion skin cells. The large, flat cell walls lie flat on the substrate.

Fig. 2 SEM photograph of the microcraters formed on onion skin cell wall when ion bombarded by $\mathrm{Ar}^{+}$ions at $20 \mathrm{keV}$ energy and $1 \times 10^{15} \mathrm{ions} / \mathrm{cm}^{2}$ dose.

Fig. 3 (a) Region of onion skin cell wall surface prior to electron beam bombardment.

(b) The same region of onion skin cell wall, after electron beam bombardment at a range of beam current levels. For each of eight different beam currents the beam was moved to focus onto a slightly displaced region of the cell surface. The progressively increasing damage can be seen.

Fig. 4 (a) Ion cascade damage region formed in onion skin cell wall (taken as $\mathrm{C}_{1} \mathrm{H}_{2} \mathrm{O}_{1}$ ) by $20 \mathrm{keV} \mathrm{Ar}^{+}$ions.

(b) Electron interaction volume for a $20 \mathrm{keV}$ electron beam into carbon. 


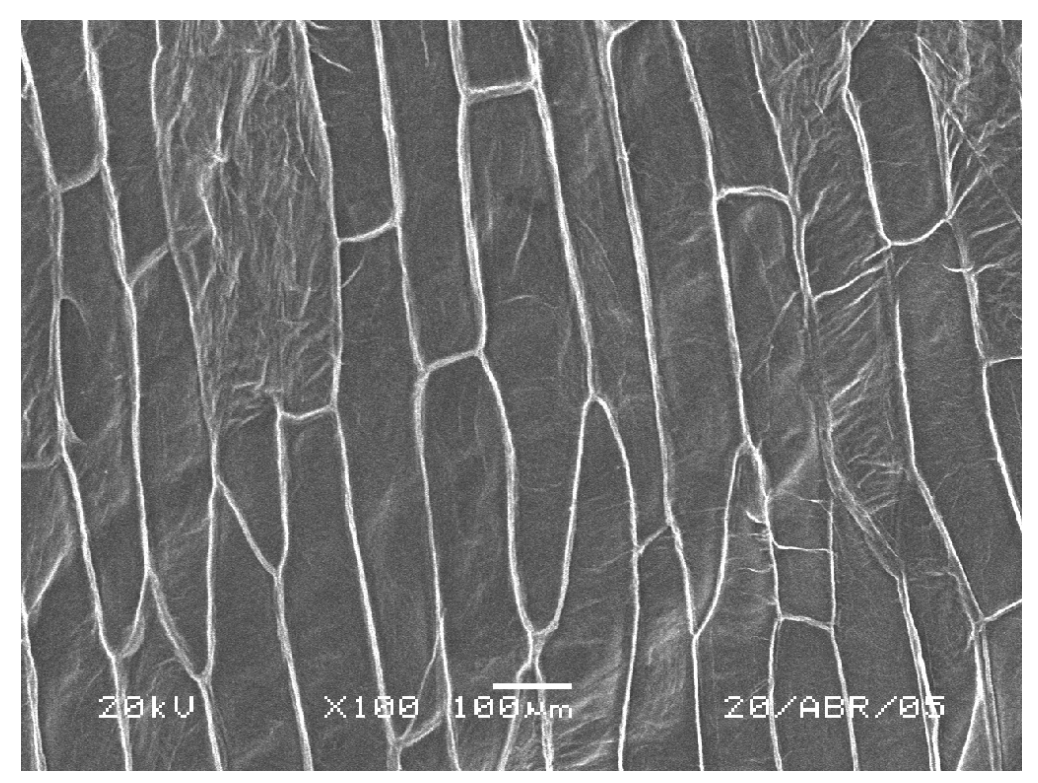

Fig. 1 


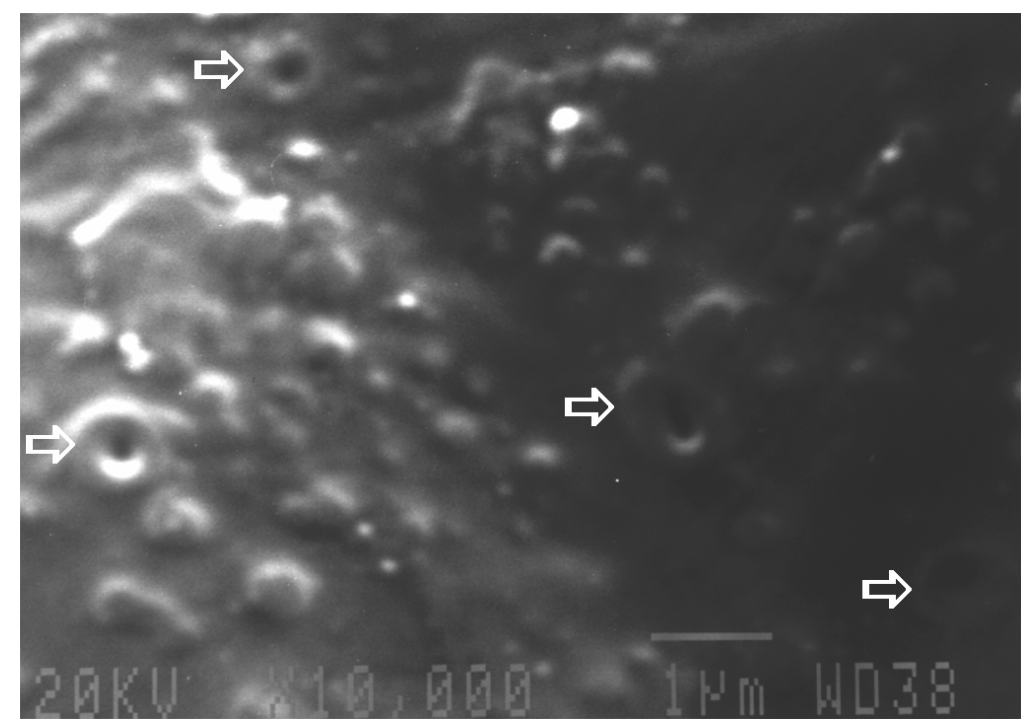

Fig. 2 


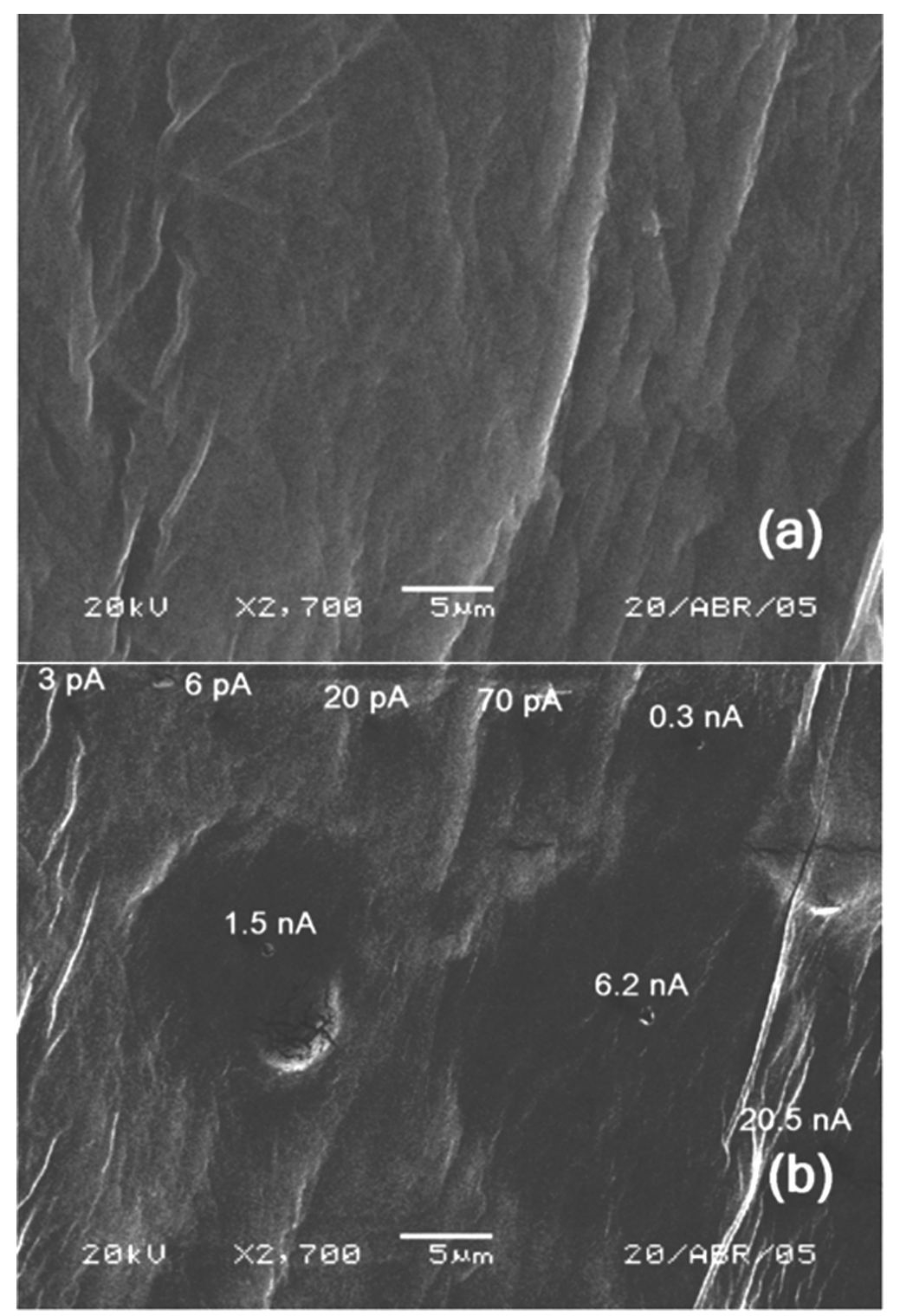

Fig. 3 


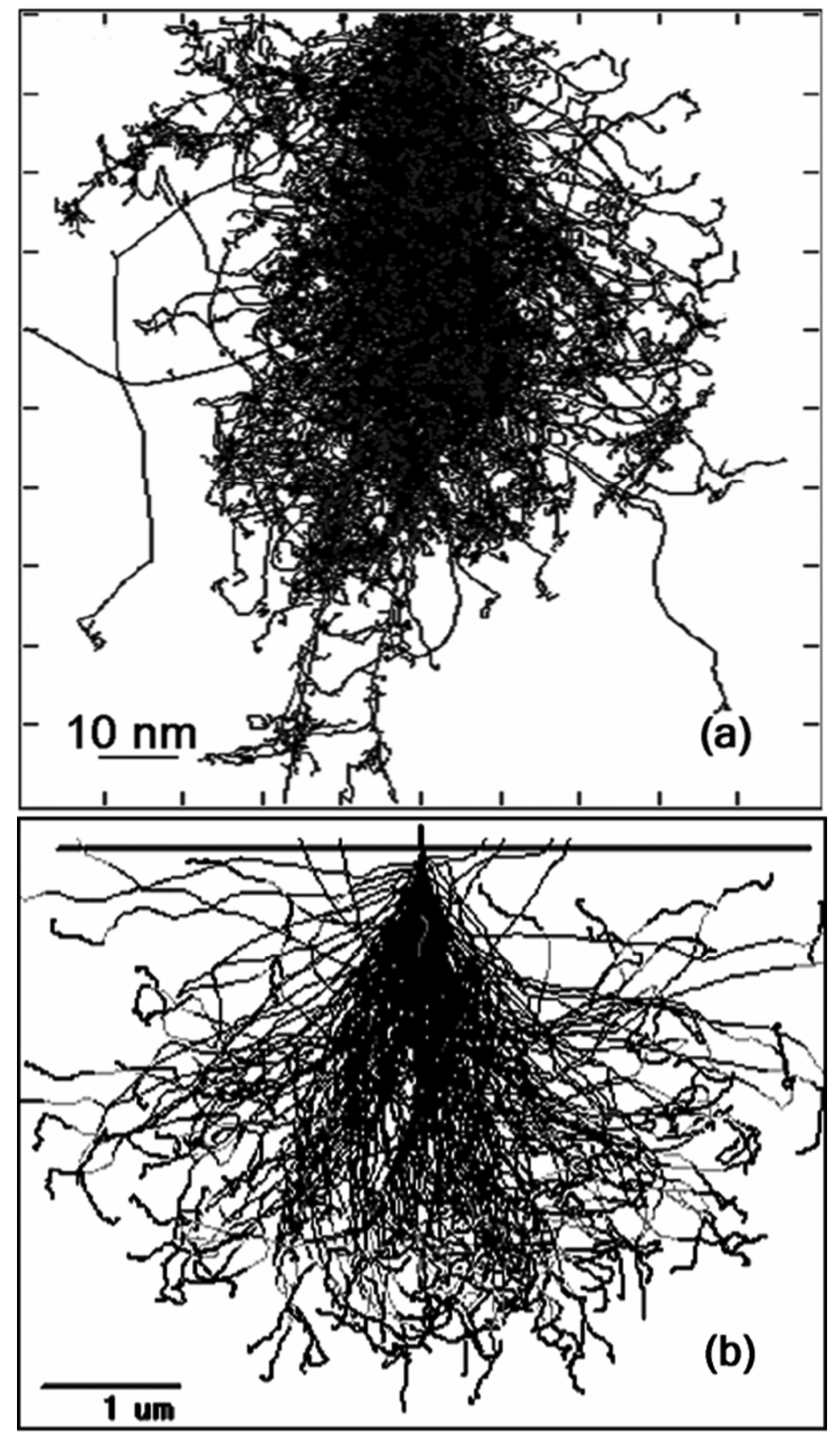

Fig. 4 